\title{
Effective Bronchodilator Resuscitation of Children in the Emergency Room: Device or Interface?
}

Aerosol therapy is a vital component in the treatment of children with asthma, and inhaled $\beta$-agonists are the firstline therapy for bronchospasm in acute asthma. In the emergency department, bronchodilators are commonly administered to children via small-volume jet nebulizer (SVN) or large-volume jet nebulizer (LVN). SVNs have been widely used in hospitals and emergency departments for more than 50 years. An SVN delivers $1-5 \mathrm{~mL}$ over 8-15 min. In the United States the drug label for inhalation solution of albuterol is a $0.083 \%$ solution $(2.5 \mathrm{mg}$ in $3 \mathrm{~mL}$ ), administered 3 or 4 times per day, but that dosage is often not sufficient to relieve a severe asthma exacerbation, even though such dosing may be sufficient for mild to moderate reactive airway disease in an ambulatory setting.

Albuterol, like most drugs approved for inhalation, was approved based on trials with ambulatory patients with mild to moderate asthma. Patients presenting to the emergency department with severe bronchospasm may not respond to the standard label dose of albuterol and require higher doses at shorter intervals than the stable patient at home. This has led clinicians to devise effective "offlabel" strategies for administration of bronchodilators and other drugs to treat severely ill patients, including higher doses, higher drug concentration, shorter intervals between doses, and continuous nebulization. Continuous nebulization with an LVN or an SVN with a continuous feed and a delivery rate of $10-20 \mathrm{mg} / \mathrm{h}$ is as effective as, or superior to, intermittent doses via SVN..$^{1-6}$ Comparison of 4 LVNs found relatively consistent emitted aerosol output, with similar performance during the first 5 hours of use. ${ }^{7}$

Breath-actuated nebulizers generate aerosol only during inhalation, which reduces aerosol waste but extends the treatment time. ${ }^{8,9}$ Since the introduction of the breath-actuated nebulizer in 2000, in vitro and in vivo studies have shown the breath-actuated nebulizer's potential for better lung deposition and possibly greater efficacy. For example, Sangwan et al compared MistyNeb and AeroEclipse for particle-size distribution in vitro, with no breathing (standing cloud), and with simulated ventilation, and reported that the mass median aerodynamic diameter (MMAD) for both nebulizers was affected by ventilation: MistyNeb $5.2 \mu \mathrm{m}$ versus AeroEclipse $4.6 \mu \mathrm{m}$ for standing cloud, and MistyNeb $3.1 \mu \mathrm{m}$ versus AeroEclipse $2.2 \mu \mathrm{m}$ during ventilation. With inhaled radio-labeled interferongamma, lung deposition averaged $68.1 \pm 0.1 \%$ with AeroEclipse, and $30.9 \pm 0.0 \%$ with MistyNeb, with fill volumes of $2 \mathrm{~mL}$ and $4 \mathrm{~mL}$, respectively. ${ }^{10}$ Those studies stimulated speculation that breath-actuated nebulizer might generate smaller aerosol particles and thus have greater lung dose with other drugs, such as bronchodilators.

Despite the widespread interest in breath-actuated nebulizers for hospital practice, precious few studies have compared breath-actuated nebulizers to other bronchodilator delivery strategies in the emergency department. In this issue of RESPIRATORY CARE, Sabato et al present findings from their randomized study of the efficacy of albuterol administered via the AeroEclipse breath-actuated nebulizer versus their institution's standard therapy (either SVN or LVN) in the treatment of pediatric patients presenting with asthma to the emergency department. ${ }^{11}$ They are the first to report significant differences in admission rate and symptom-score improvement between the 2 treatment groups. Sabato and colleagues made a multidimensional assessment, including clinical asthma score, heart rate, respiratory rate, peak expiratory flow, patient tolerance of the treatment, nausea, tremor, vomiting, and hyperactivity. Those variables are the best way to capture all domains of patients' response to therapy, and they were measured at baseline and at follow-up to determine changes in health status. From the statistical point of view, the study was appropriately powered and had a very small sample loss, which are strengths of the study.

See the Original Study on Page 761

Sabato's team at Children's Hospital and Research Center Oakland has over 2 decades of experience in innovating "off-label" strategies for treating severe asthma in the emergency department. In addition to use of undiluted bronchodilator delivered via SVN, since 1985, Benton et al described effective bronchodilator response with titration to effect with 4-14 puffs from a pressurized metered-dose inhaler with valved holding chamber. ${ }^{12}$ The quest to develop effective bronchodilator techniques in their busy urban emergency department resulted in development of aggressive, innovative strategies that evolved into their standard asthma algorithm, in which patients with less 
severe symptoms receive SVN, and sicker patients receive continuous nebulization via LVN. The nominal and emitted doses depend on patient weight: SVN dose $2.5 \mathrm{mg}$ in $0.5 \mathrm{~mL}$ for patients $<20 \mathrm{~kg}$, and $5 \mathrm{mg}$ in $1 \mathrm{~mL}$ for larger patients; LVN dose $10 \mathrm{mg}$ in $20 \mathrm{~mL}$, administered over one hour.

This background of aggressive therapy makes it even more remarkable that Sabato et al found that the AeroEclipse breath-actuated nebulizer was associated with fewer hospital admissions than their standard therapy. The study poses some challenges to the reader in interpreting the data to determine how to apply the lessons learned into practice.

\section{Is Breath-Actuated Nebulizer Superior to SVN?}

No randomized trials have demonstrated greater bronchodilator efficacy with breath-actuated nebulizer than with SVN in the emergency department. This trend continues in the study by Sabato et al, who report that the admission rate with breath-actuated nebulizer and SVN were both $40 \% .{ }^{11}$ The mean clinical asthma score was lower in the SVN group (3.0) than in the AeroEclipse group (5.1). The results suggest that in patients with less severe asthma the SVN was as effective as AeroEclipse, but the comparison is complicated by the relatively small number of patients who received SVN (10 patients) versus AeroEclipse (86 patients). While AeroEclipse may be more effective than SVN in patients with more severe asthma, this was not evaluated by Sabato et al.

\section{Is Breath-Actuated Nebulizer Superior to Continuous Nebulization?}

To answer this question, the first step is to analyze the devices' output. The high-flow MiniHeart nebulizer has a listed output of $20 \mathrm{~mL} / \mathrm{h}$ and an MMAD of 2-3 $\mu \mathrm{m}$, which corresponds to a respirable fraction of $>70 \%$. In contrast, the AeroEclipse has a claimed MMAD of $2.8 \mu \mathrm{m}$ and a $78 \%$ respirable fraction. Those characteristics are used in the following example.

With an inspiratory-expiratory ratio of $1: 4$ in a child with moderate to severe bronchospasm, $20 \%$ of the emitted dose of $10 \mathrm{mg}(10 \mathrm{mg} \times 0.2=2 \mathrm{mg})$ is inhaled, and $70 \%$ of the respirable particles, or $1.4 \mathrm{mg}$ $(2 \mathrm{mg} \times 0.7=1.4 \mathrm{mg})$ of albuterol could reach the lung. If $35 \%$ of the breath-actuated nebulizer dose is inhaled, and the respirable fraction is $78 \%$, a respirable dose of approximately $1.4 \mathrm{mg}(5.0 \mathrm{mg} \times 0.35 \times 0.78=1.4 \mathrm{mg})$ could be achieved with the 5-mg dose, and approximately $0.7 \mathrm{mg}(2.5 \mathrm{mg} \times 0.35 \times 0.78=0.68 \mathrm{mg})$ with the 2.5-mg dose. Although this example does not account for the residual drug remaining in the MiniHeart nebulizer at the end of nebulization (possibly $0.5-1.0 \mathrm{mg}$ of albuterol), it does indicate a similar lung dose with the $5 \mathrm{mg}$ breathactuated nebulizer dose and the $10 \mathrm{mg} / \mathrm{h} \mathrm{LVN}$ dose.

\section{If the Inhaled Dose Is Similar Between Breath-Actuated Nebulizer and LVN, What Other Factors Apply?}

Although Sabato et al identified a relationship between the admission rate and the first bronchodilator treatment administered in the emergency department, it is unclear how many aerosol treatments were required for any one patient. As a group, 69\% of the AeroEclipse group required additional bronchodilator treatments, compared to $57 \%$ of the standard-therapy group. To understand the causal relationship between treatment and admission, we need to understand how many total doses were administered.

The AeroEclipse and SVN treatments were administered by respiratory therapists who remained at the bedside during the treatments, which assures that the aerosol was in fact administered and tolerated through the treatment. In contrast, after initial setup, the continuous nebulization via LVN was largely overseen by the parent, and was not supervised by the respiratory therapist, so we are not sure how much of each LVN treatment was actually administered during the LVN treatment hour. One might infer that aerosol therapy directly observed by a clinician is more reliable and effective than unobserved therapy.

\section{Is Interface the Key?}

The LVN patients were sicker than the AeroEclipse patients (clinical asthma score 5.5 vs 5.1, respectively). However, the key to the difference in hospital admission may be associated more with the interface than with the aerosol generators. Treatment tolerance was greater in the AeroEclipse group than the standard-therapy group. Blow-by was used in $23 \%$ of the standard-therapy group, and in less than $4 \%$ of the AeroEclipse group. If the therapeutic benefit of blow-by is negligible, then this difference in interface may account for much of the difference in therapeutic response.

Sabato et al report that more of the AeroEclipse patients tolerated mask, which might indicate that breathactuation is better tolerated than continuous nebulization, which involves cold aerosol blowing onto the face between breaths. ${ }^{11}$ This aspect of aerosol therapy has not been well studied and merits further investigation. Loose-fitting mask and blow-by dramatically reduce aerosol deposition. ${ }^{13-21}$ Lung dose is less than $1 \%$ with a face mask leak of $\geq 0.2 \mathrm{~cm}^{2},{ }^{13}$ so optimal mask/face seal is important in maximizing aerosol delivery. Blow-by decreases aerosol delivery with the distance between the face and mask, ${ }^{20}$ so variability in mask/face 


\section{EfFective Bronchodilator Resuscitation of Children in the Emergency Room}

distance during the LVN treatment hour with an untrained parent administering blow-by may have been a large factor in inhaled dose. Therefore, the trend toward better clinical asthma score and difference in admission rate may be associated with patient tolerance of the patient/device interface with AeroEclipse.

A key issue in aerosol therapy in children is intolerance of the interface. We must use an interface the patient will tolerate, so improvements that make the interface more tolerable may be more important than the type of aerosol generator. It is well known that screaming, struggling, and crying decrease aerosol delivery to children, ${ }^{17,22,23}$ whereas tolerance is associated with greater lung deposition and better adherence to therapy. For instance, Janssens et al ${ }^{24}$ compared aerosol delivery in awake and asleep children and found that lung dose was significantly higher in the sleeping children. When the interface is better tolerated, it causes less agitation and leads to better deposition and outcomes. Up to $49 \%$ of infants and children do not tolerate aerosol via mask without agitation, which decreases deposition, and with blow-by the lung delivery is negligible. This is a problem in the emergency department and at home, and is associated with low adherence to therapy.

A better-tolerated interface may be the key to more effective therapy. Recent research on aerosol delivery via highflow nasal cannula to pediatric patients was promising. ${ }^{25,26}$ Infants and children have preferential nasal breathing and tolerate nasal cannula better than mask, and in vitro studies suggested that delivery via nasal cannula provided a high inhaled dose and may be worthy of further evaluation. ${ }^{25,26}$

Sabato et al address a very important research question: comparing breath-actuated nebulizer to LVN and SVN. ${ }^{11}$ If breath-actuated nebulizer and LVN have similar particle-size distributions and respirable dose, then any differences in clinical response are more about the interface than about the aerosol generator. The observation that AeroEclipse with mask was better tolerated by children with severe asthma may provide an important insight into the observed difference in hospital admission. Through additional research we can determine the best aerosol delivery method for children in the emergency department and determine the effect of each device/interface in children with asthma. Therefore, future studies should concentrate not only on aerosol devices but also on patientrelated factors that affect aerosol delivery in children of all ages, races, and ethnicities.

\footnotetext{
Arzu Ari PhD RRT PT CPFT James B Fink PhD RRT FAARC Division of Respiratory Therapy School of Health Professions Georgia State University Atlanta, Georgia
}

\section{REFERENCES}

1. Kelly H, Keim K, McWilliams B. Comparison of two methods of delivering continuously nebulized albuterol. Ann Pharmacother 2003; 37(1):23-26.

2. Papo MC, Frank J, Thompson AE. A prospective, randomized study of continuous versus intermittent nebulized albuterol for severe status asthmaticus in children. Crit Care Med 1993;21(10): 1479-1486.

3. Khine H, Fuchs SM, Saville AL. Continuous vs intermittent nebulized albuterol for emergency management of asthma. Acad Emerg Med 1996;3(11):1019-1024.

4. Camargo CA Jr, Spooner CH, Rowe BH. Continuous versus intermittent beta-agonists in the treatment of acute asthma. Cochrane Database Syst Rev 2003;(4):CD001115.

5. Fink J, Dhand R. Bronchodilator resuscitation in the emergency department, part 1: device selection. Respir Care 1999;44(10):13531374.

6. Reisner C, Kotch A, Dworkin G. Continuous versus frequent intermittent nebulization of albuterol in acute asthma: a randomized prospective study. Ann Allergy Asthma Immunol 1995;75(1): 41-47.

7. Berlinski A, Willis JR, Leisenring T. In-vitro comparison of 4 largevolume nebulizers in 8 hours of continuous nebulization. Respir Care 2010;55(12):1671-1679.

8. Ari A, Hess D, Myers TR, Rau JL. A guide to aerosol delivery devices for respiratory therapists, 2nd edition. Irving, TX: American Association for Respiratory Care; 2009. http://www.aarc.org/educa tion/aerosol_devices/aerosol_delivery_guide2.pdf. Accessed April 12, 2011.

9. Rau JL, Ari A, Restrepo RD. Performance comparison of nebulizer designs: constant-output, breath-enhanced, and dosimetric. Respir Care 2004;49(2):174-179.

10. Sangwan S, Condos R, Smaldone G. Lung deposition and respirable mass during wet nebulization. J Aerosol Med 2003;16(4); 379-386

11. Sabato K, Ward P, Hawk W, Gildengorin V, Asselin JM. Randomized controlled trial of a breath-actuated nebulizer in pediatric asthma patients in the emergency department. Respir Care 2011;56(6):761770 .

12. Benton G, Thomas RC, Nickerson BG, McQuitty JC, Okikawa J. Experience with a metered-dose inhaler with a spacer in the pediatric emergency department. Am J Dis Child 1989;143(6):678681

13. Esposito-Festen JE, Ates B, van Vliet FJ, Verbraak AF, de Jongste JC, Tiddens HA. Effect of a facemask leak on aerosol delivery from a pMDI-spacer system. J Aerosol Med 2004;17(1):1-6.

14. Smaldone GC, Sangwan S, Shah A. Facemask design, facial deposition, and delivered dose of nebulized aerosols. J Aerosol Med 2007;20(Suppl 1):S66-S75.

15. Rau JL, Smaldone GC. The interface between the device and the patient: masks, mouthpieces, and "others". Introduction. J Aerosol Med 2007;20(Suppl 1):S1-S2.

16. Janssens H, Tiddens H. Aerosol therapy: the special needs of young children. Pediatr Respir Rev 2006;7(Suppl 1):S83-S85.

17. Janssens HM, Tiddens HA. Facemasks and aerosol delivery by metered dose inhaler-valved holding chamber in young children: a tight seal makes the difference. J Aerosol Med 2007;20(Suppl 1):S59S63.

18. Erzinger S, Schueepp KG, Brooks-Wildhaber J, Devadason SG, Wildhaber JH. Facemasks and aerosol delivery in vivo. J Aerosol Med 2007;20(Suppl 1):S78-S83 


\section{Effective Bronchodilator Resuscitation of Children in the Emergency Room}

19. Restrepo RD, Dickson SK, Rau JL, Gardenhire DS. An investigation of nebulized bronchodilator delivery using a pediatric lung model of spontaneous breathing. Respir Care 2006;51(1):56-61.

20. Lin HL, Restrepo RD, Gardenhire DS, Rau JL. Effect of face mask design on inhaled mass of nebulized albuterol, using a pediatric breathing model. Respir Care 2007;52(8):1021-1026.

Dr Fink has disclosed relationships with Aerogen, Dance Pharmaceuticals, Airies, Cubist, and Boehringer Ingelheim. Dr Ari has disclosed no conflicts of interest.

Correspondence: Arzu Ari PhD RRT PT CPFT, Division of Respiratory Therapy, School of Health Professions, Georgia State University, PO Box 4019, Atlanta GA 30302-4019. E-mail: arzuari@ hotmail.com.

DOI: $10.4187 /$ respcare.01375
21. Rubin BK. Bye-bye, blow-by (editorial). Respir Care 2007;52(8): 981

22. Everard ML. Inhaler devices in infants and children: challenges and solutions. J Aerosol Med 2004;17(2):186-195.

23. Everard ML. Aerosol delivery to children. Pediatr Ann 2006;35(9): 630-636.

24. Janssens H, van der Wiel E, Verbraak A, de Jongste J, Merkus P, Tiddens $\mathrm{H}$. Aerosol therapy and the fighting toddler: is administration during sleep an alternative? J Aerosol Med 2003;16(4):395-400.

25. Ari A, Harwood R, Sheard M, Dailey P, Fink JB. In vitro comparison of heliox and oxygen in aerosol delivery using pediatric high flow nasal cannula. Pediatr Pulmonol 2011;[Epub ahead of print]. doi: 10.1002/ppul.21421

26. Bhashyam AR, Wolf MT, Marcinkowski AL, Saville A, Thomas K, Carcillo JA, Corcoran TE. Aerosol delivery through nasal cannulas: an in vitro study. J Aerosol Med Pulm Drug Deliv 2008;21(2):181188 